International Journal of English Literature and Social Sciences
Vol-6, Issue-5; Sep-Oct, 2021

Peer-Reviewed Journal

\title{
Misconception on floating and sinking
}

\section{Ugyen Dorji}

Department of School Education, Buli Central School, Bhutan

Email: ugyen12@education.gov.bt

Received: 21 Sep 2021; Received in revised form: 15 Oct 2021; Accepted: 21 Oct 2021; Available online: 28 Oct 2021

(C)2021 The Author(s). Published by Infogain Publication. This is an open access article under the CC BY license

(https://creativecommons.org/licenses/by/4.0/).

\begin{abstract}
The aim of the study was to identify the misconceptions on floating and sinking amongst the Bhutanese students of grade IX, examined the strategies to remedy and eliminate these misconceptions. A total of 15 ninth grade students participated in the study. The study employed quantitative approach using two-tier diagnostic test. The study found that participants had misconceptions on floating and sinking of an object. The participants directly link weight and volume of an object to its floatation and sinking. However, most of the misconceptions on floating and sinking of object were cleared after having an intervention by using group activity-based questioning and learning.
\end{abstract}

The study also found that the diagnostic items designed to identify students' misconceptions and classroom activities designed to treat those misconceptions were effective and efficient. So, similar approaches can be taken to address common misconceptions and help students to establish scientific conceptions in other content areas of science education. Further, the present study focused had only few participants, a study may be carried out by using more sample size to get a deep understanding of the subject.

Keywords_Misconception, floating, sinking, density.

\section{INTRODUCTION}

When students enter the classroom, they often hold prior knowledge or conceptions about the natural world which has been influenced by textbooks, teachers' explanations or everyday language (Yin et a., 2008). According to Hardy et al. (2006) students often construct their own knowledge and theories about how the natural world works. Therefore, their construction of knowledge or theories may sometimes be contrary to scientific point of view, constituting what is referred to as misconceptions.

Over the last 20 years, educators have shown great interest in identifying students' misconceptions about various science phenomena, either before or following an instruction. One of the areas that science education and cognitive development research have studied is floatation (Unal, 2016). Misconceptions are barriers to learning, addressing the misconceptions is essential in students learning. Therefore, this study aimed to investigate
Bhutanese grade-nine students 'conceptions, understandings and misunderstandings of sinking and floating concepts.

\section{PROBLEM STATEMENT}

Students have misconception regarding how the object float and sink. Students are considering weight of the materials as the only criterion when predicting whether a material will float or sink. However, it is impossible to decide categorically if a material is heavy or not when there is no further point of reference. One cannot claim that that gold is heavier than feathers because amount of each is a vital factor- a barrel of feathers would be heavier than a single gold ring. To make fair comparisons of heavier/lighter pupil should consider how much of a material is in there; in science this is done by assessing the amount of space each object takes up, that is its volume. The scientific concept of density gets around the problem 
by taking in account how much an object weighs (its mass) as well as its volume (Bar et al.,1994).

The concept sinking and floating is taught in middle secondary schools. Although sinking and floating is a common phenomenon in everyday life, it is a sophisticated science topic. To fully understand the fundamental reasons for floating and sinking, requires complicated knowledge that includes an analysis of forces (buoyancy and gravity) and water pressure. The knowledge to fully understand the fundamentals of floating and sinking, either not introduced or not sufficiently addressed in secondary school curricula. Rather, some curriculum developers take a shortcut and use relative density as a simplified explanation for why some object sink and float. Therefore, the purpose of this study is to find out the misconceptions on floating and sinking. It also aimed to find factors that cause misconceptions and how to address it.

\section{RESEACRH QUESTIONS}

Main question: How instructions based on activity-based (group) learning change students' misconceptions on floating and sinking?

\section{Sub questions:}

1.What are some misconceptions on floating and sinking?

2.How misconceptions on floating and sinking be addressed?

Aim: The aim of the study is to identify the misconception of the 9th graders regarding floating and sinking in the context of the unit on liquid pressure by the use of activitybased learning technique.

\section{Objectives}

1.Identify some misconception in floating and sinking.

2.Address the misconception by using conceptual test.

\section{Significance}

The research carried out will benefit the curriculum planners, teachers and students as a whole. Further, the information generated from this study could be the guidelines for the present and future physics teachers and students.

\section{LITERATURE REVIEW}

This topic will highlight the findings of earlier research on the misconceptions of floating and sinking in the context of the unit on liquid pressure. In the literature review the author talks about $3 \mathrm{C}$ 's that are compare, contrast and connect the major theories, methodologies, approaches and controversies on the topic. In this study the review covers some misconceptions of floating and sinking and how to address these misconceptions.

\section{Misconceptions on floating and sinking}

Misconception is one of the most frequently studied topics in science teaching and learning. Identifying students' misconceptions about various science phenomenon has been a concern over the last few decades. One of the areas that science education and cognitive development research have studied is floatation and sinking (Ünal \& Coştu, 2005). Macaroglu and Şenturk (2001) also carried out a study to check the fourth-grade students' understanding of the word 'floatation'. The study found that are not able to identify whether the materials sank or floated, due to their non-scientific rules for sinking and floating.

An interview carried by Moller (1999) with elementary as well as secondary school students showed that children's explanations often focus on one dimension only such as things that are light will float, large things will sink or everything with holes in it will sink. Moreover, in many explanations, air is seen as an active force that pulls objects upward and water is seen as a force that sucks them downward (Hardy et al., 2006). These explanations of floating and sinking are not in line with scientific explanations since, rather than consider the relationship between object and surrounding fluid, the students focus on single property of object that is weight. Further a study done by Unal (2016) reveals that most of the students' difficulties in understanding about floatation and sinking were due to incomplete ideas about underlying concepts such as volume, mass, density, force, and pressure. This also indicates that students are retaining their ideas in a fragmented manner (Çalik, 2005). Taúdere and Ercan (2011) in their study found out that students had some misconceptions stated in the expressions such as density of swimming objects is equal to the density of liquid, the densities of sunken objects in the liquid are equal and buoyancy of sunken objects in the liquid is equal to the weight of the objects.

Most of the students had misconceptions regarding floating and sinking due to their preconceived knowledge of the topic. In particular, activity of building relations between existing knowledge and new knowledge plays an important role when interpreting students' learning as a process of conceptual understanding. By reviewing the possible source of misconceptions, it is suggested that conceptual development can be promoted by classroom instruction that avoids excessive factual details, establishes meaningful connection between new and existing concepts, and takes into account students' prior knowledge (Etmeni \& Students, 2000). One of the strategies used to 
eliminate the misconception is the employment of group activity as an intervention strategy.

\section{METHODOLOGY}

The research design of the present study is a case study with quantitative approach using two-tier diagnostic test for collection of data. Data analysis was done by using Microsoft excel 2019. The study was implemented to a total of 15, 9th graders of Samtse Higher Secondary School. In order to identify misconceptions, the students were given hands-on activity design having pre-test and post-test. After the pre-test and analysis of pre-test, the misconceptions were identified and taught the concept in class through hands-on activity based. For this study, the questionnaire was adopted from a case study done by Yin et al. (2008), which consist of eight fill in the blank questions with pictures. The questions were designed in such a way that if questions are confusing, the confusions can be clarified by the pictorial representations of the questions. After intervention post-test data were collected and analyzed.

\section{SAMPLING}

The study was conducted with 15 ninth-grade students (7 girls and 8 boys) at one of the schools in Bhutan. The class was randomly chosen. The ages of the participants were ranged from 16 to 18 years.

\section{Research Instruments}

In this study two sets of the questions adopted from Yin et al. (2008) based on the concept of floating and sinking were used to collect the data. Intervention was done by using activity-based learning. The question consists of eight fill in the blank questions with pictorial representations of the questions.

\section{Data analysis}

The analysis of data was done by using Microsoft excel sheet. Analysis of pre-test and post-test data are mentioned in result and discussion.

\section{RESULT AND DISCUSSION}

Data analysis of pre-test:

The questions are adopted from Yin et al. (2008).

\begin{tabular}{|l|l|l|l|l|l|l|}
\hline $\begin{array}{l}\text { Questions } \\
\text { Attached } \\
\text { appendix) }\end{array}$ & $\begin{array}{l}\text { Correct } \\
\text { Answer }\end{array}$ & Float & Sink & $\begin{array}{l}\text { Total } \\
\text { Responded }\end{array}$ & $\begin{array}{l}\text { Correct } \\
\text { response } \\
(\%)\end{array}$ & $\begin{array}{l}\text { Incorrect } \\
\text { response } \\
(\%)\end{array}$ \\
\hline Q1 & Float & 8 & 7 & 15 & $53.3 \%$ & $46.6 \%$ \\
\hline Q2 & Sink & 11 & 4 & 15 & $26.6 \%$ & $73.3 \%$ \\
\hline Q3 & Float & 4 & 11 & 15 & $26.6 \%$ & $73.3 \%$ \\
\hline Q4 & Sink & 15 & 0 & 15 & $0 \%$ & $100 \%$ \\
\hline Q5 & Float & 8 & 7 & 15 & $53.3 \%$ & $46.6 \%$ \\
\hline Q6 & Sink & 9 & 6 & 15 & $40 \%$ & $60 \%$ \\
\hline Q7 & & & & & & \\
\hline Q8 & Float & 3 & 12 & 15 & $20 \%$ & $80 \%$ \\
\hline
\end{tabular}

Fig.1: Pre-test Data

From the above figure, out of eight questions, most of the students have misconceptions about floating and sinking in following questions:

\begin{tabular}{|l|l|l|}
\hline Questions & Correct response & Incorrect response \\
\hline Q2 & $26.6 \%$ & $73.3 \%$ \\
\hline Q3 & $26.6 \%$ & \\
\hline Q4 & & $73.3 \%$ \\
\hline Q7 & $0 \%$ & $100 \%$ \\
\hline
\end{tabular}

Fig.2: Questions With Misconceptions

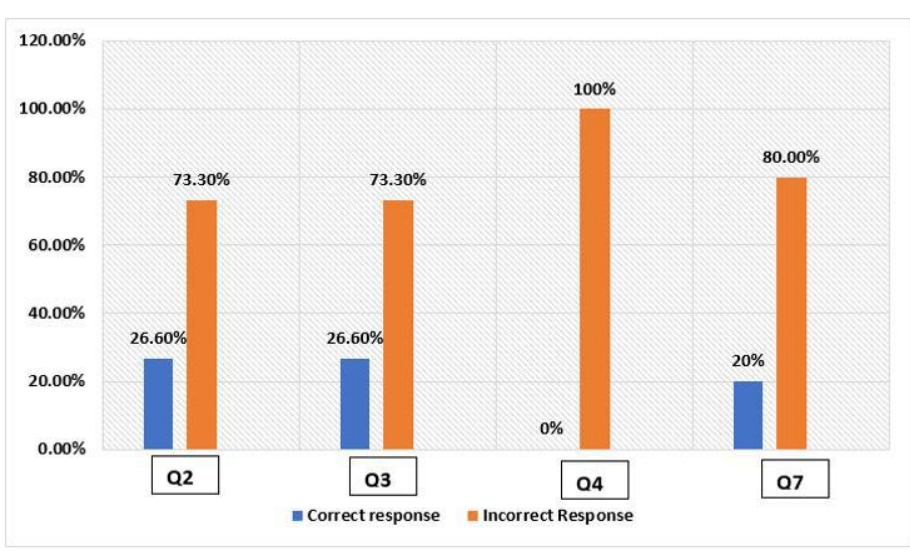

Fig.3: Graph of Pre-test Misconception Questions

The figure above shows that $73.3 \%$ of students responded incorrectly for the statement Q2 and Q3, so there is misconception in terms of solid and hollow balls though it have same mass and volume. For the statement of Q4, $100 \%$ of students responded incorrectly that means students are confused with regards to volume, where they consider surface area as the only means to calculate volume. This was in line with a study done by Unal in 2016 where he found out that most of the students facing difficulties in understanding the concept of floatation and 
sinking were due to incomplete ideas about volume, mass, density, force, and pressure. Further in Q7, $80 \%$ of the students responded incorrectly, that means students have misconception that soft things will float because its soft and hard things will sink because it's hard.

\section{Intervention}

The development of lesson plan using activity-based learning and questioning will help to clear the misconception. The lesson plan is designed as follows;

\section{Class : IX}

School :

\section{Subject : Physics}

Topic : Density

\section{Strategy : Activity-based learning}

\section{Lesson Introduction.}

Teacher greets the students and introduce the topic density to the students. Ask the following questions to relate and check the previous knowledge;

1. Can anyone tell me why some object sinks and some float?

2. What are some of the factors on which floating and sinking of objects depends upon?

Reinforce each student who answered with different reinforcements.

\section{Lesson Development}

Teacher demonstrate.

\section{Divide the students in groups of their interest.}

\section{Materials required for Each Group:}

Electronic scale

A large container

A candle

A marble

A rubber ball

A hollow ball

\section{Procedures:}

Procedure 1: Weigh the masses of the candle, the marble, hollow ball and the rubber ball by using an electronic scale. Write down the masses of the objects in the table.

\begin{tabular}{|l|l|}
\hline Objects & Weights \\
\hline The candle & \\
\hline The marble & \\
\hline The rubber ball & \\
\hline Hollow ball & \\
\hline
\end{tabular}

Guess which object will sink or float.

Procedure 2: Fill the container with water. Afterwards, put the candle, the marble, hollow ball and the rubber ball into the container gently. What did you observe? Which sank or floated? Were your earlier predictions correct? Compare what you have predicted and the result of the experiments.

Now you all have got the difference between your prediction and you result, now fill up the form provided.

Lesson Closure: So, from today lesson, we have seen that it's not only the weight of the object that should be considered while identifying whether the object sink or float. The main purpose for todays' lesson is objects sinking and floatation depends upon the density of the objects.

\section{Data analysis of post-test}

\begin{tabular}{|l|l|l|}
\hline Questions & Correct response & Incorrect response \\
\hline Q2 & $53.3 \%$ & $46.6 \%$ \\
\hline Q3 & $60 \%$ & \\
\hline Q4 & & $20 \%$ \\
\hline Q7 & $50 \%$ & $50 \%$ \\
\hline
\end{tabular}

Fig.3: Post-test Data

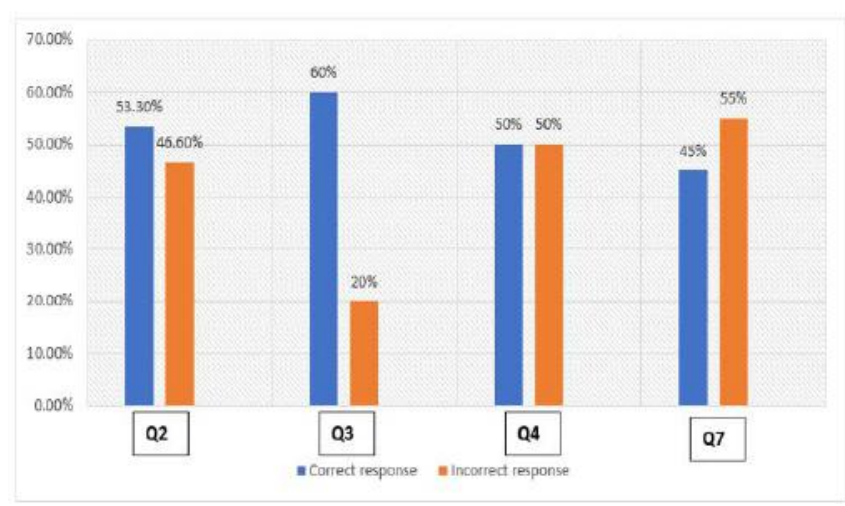

Fig.4: Graph of Post-test Misconception Question

The figure above shows that $53.3 \%$ of students responded correctly for the statement Q2 and 60\% of the students responded correctly for $\mathrm{Q} 3$, so that means misconceptions regarding Q2 and Q3 has been addressed. For Q4, there is increased in $50 \%$ of students who responded correctly which indicates students' misconceptions in Q4 couldn't be addressed properly. However, in Q7, 55\% of the 
students responded correctly, that means students found remedy from the intervention and have cleared their misconception.

Analysis of the pre-test revealed that students are having misconceptions on following aspects:

i. Floating and sinking of Solid ball, softball and hollow ball

ii. Floatation and sinking of flat and non-flat objects.

\section{Comparison between pre-test and post-test}

\begin{tabular}{|c|c|c|c|c|}
\hline & \multicolumn{2}{|l|}{ Pre-test } & \multicolumn{2}{|l|}{ Post-test } \\
\hline Questions & $\begin{array}{l}\text { Correct } \\
\text { Response }\end{array}$ & $\begin{array}{l}\text { Incorrect } \\
\text { Response }\end{array}$ & $\begin{array}{l}\text { Correct } \\
\text { Response }\end{array}$ & $\begin{array}{l}\text { Incorrect } \\
\text { Response }\end{array}$ \\
\hline Q2 & $26.6 \%$ & $73.3 \%$ & $53.3 \%$ & $46.6 \%$ \\
\hline Q3 & $26.6 \%$ & $73.3 \%$ & $60 \%$ & $20 \%$ \\
\hline Q4 & $0 \%$ & $100 \%$ & $50 \%$ & $50 \%$ \\
\hline$Q^{7}$ & $20 \%$ & $80 \%$ & $45 \%$ & $55 \%$ \\
\hline Total Responded & \multicolumn{4}{|c|}{15} \\
\hline
\end{tabular}

Fig.5: Comparison of Pre-test and Post-test

From the above figure, it revealed that compared to pretest the results of post-test have significantly improved after the intervention, which indicates misconceptions are addressed through group activity. However, in question 4 and 7 , though compared to pre-test there is increase in number of students who responded correctly but there is no significant rise in the correct response even after the intervention. The reason for this could be, students might be confused since intervention was done for a short period of time due to time constraint.

\section{CONCLUSION}

Bhutanese grade nine students have difficulties in understanding sinking and floating, and have misconceptions about the phenomena as reported earlier. Students cannot identify the factors influencing whether an object sinks or floats in a liquid. When deciding whether an object sinks or floats, they consider their mass, or volume instead of density. They also consider irrelevant factors such as whether it has a hole, its size or the volume of the liquid. When these misconceptions about sinking and floating are examined, it was found that students have misconceptions because of their experiences in daily life, lack of knowledge and overgeneralization.

The diagnostic items designed to identify students' misconceptions and classroom activities designed to treat those misconceptions were effective and efficient. So similar approaches can be taken to address common misconceptions and help students establish scientific conceptions in other content areas of science education.

\section{LIMITATIONS}

Universality is one of the most obvious and common limitations of a misconception, that is, some conceptions might work well in some situations however not in others (Yin et al, 2008). Some of the limitations of present study are; universality, time constraint, no standard number of students, no proper response from the students and lack of resources.

\section{ACKNOWLEDGEMENTS}

An acknowledgement section may be presented after the conclusion, if desired.

\section{REFERENCES}

[1] Bar, V., Zinn, B., Goldmuntz, R. \& Sneider, C. (1994). Children's conceptions about weight and free fall. Science Education, 78, 149-169.

[2] Butts, D. P., Hofman, H. M., \& Anderson, M. (1993). Is hands-on experience enough? A study of young children's views of sinking and floating objects. Journal of Elementary Science Education, 5(1), 50.

[3] Çalık, M. (2005). A cross-age study of different perspectives in solution chemistry from junior to senior high school. International Journal of Science and Mathematics Education, 3: 671-696.

[4] Çepni, S., Şahin, Ç., \& Ipek, H. (2010, December). Teaching floating and sinking concepts with different methods and techniques based on the 5E instructional model. In Asia-Pacific Forum on Science Learning and Teaching (Vol. 11, No. 2, pp. 1-39). The Education University of Hong Kong, Department of Science and Environmental Studies.

[5] Etmeni, N. D. A. V., \& Students, I. (2000). AS BARRIER TO UNDERSTANDING, (Yip 1998).

[6] Hardy, I., Jonen, A., Möller, K., \& Stern, E. (2006). Effects of instructional support within constructivist learning environments for elementary school students' understanding of "floating and sinking." Journal of Educational Psychology, 98(2), 307-326. doi:10.1037/0022-0663.98.2.307

[7] Havu-Nuutinen, S. (2005). Examining young children's conceptual change process in floating and sinking from a social constructivist perspective. 
International Journal of Science Education, 27(3), 259-279. doi:10.1080/0950069042000243736

[8] Howe, C., Tolmie, A., \& Rodgers, C. (1990). Physics in the primary school: Peer interaction and the understanding of floating and sinking. European Journal of Psychology of Education, 5(4), 459475. doi:10.1007/bf03173132

[9] Macaroglu, E. \& Sentürk, K. (2001). Development of Sinking and Floating Concepts in Students'Mind. Symposium on Science Education in New Millennium, Education Faculty of Maltepe University, Istanbul, Turkey

[10] Mo“ller, K. (1999). Konstruktivistisch orientierte Lehr-Lernprozessforschung im naturwissenschaftlichtechnischen Bereich des Sachunterrichts [Research of constructivist learning and teaching processes in science and technical domains of science instruction]. In W. Ko“hnlein (Ed.), Vielperspektivisches Denken im Sachunterricht [Thinking in multiple perspectives in science education] (pp. 125-191). Bad Heilbrunn, Germany: Klinkhardt

[11] Stepans, J. I., Beiswenger, R. E., \& Dyche, S. (1986). Misconceptions die hard. The Science Teacher, 53(6), 65-69.

[12] Taúderea, A., \& Ercan, F. (2011). An alternative method in identifying misconceptions: structured communication grid. Procedia Social and Behavioral Sciences 15 (2011) 2699-2703.

[13] Thompson, F., \& Logue, S. (2006). An exploration of common student misconceptions in science. International education journal,7(4), 553559.

[14] Tomasini, N. G. (1990). Teaching Strategies and Conceptual Change: Sinking and Floating at Elementary School Level.

[15] Unal, S. (2016). Changing students' Misconception of FLoating and sinking Using Hands-on Activities. ISSN 1648-3898.

[16] Ünal, S., \& Costu, B. (2005). Problematic issue for students: Does it sink or float? Asia-Pacific Forum on Science Learning and Teaching, Volume 6, Issue 1, Article 3, p.1 (Jun., 2005).

[17] Vella, D. (2015). Floating Versus Sinking. Annual Review of Fluid Mechanics, 47(1), 115135. doi:10.1146/annurev-fluid-010814-014627

[18] Yin, Y., Tomita, M. K., \& Shavelson, R. J. (2008). Diagonosing and Dealing with students misconceptions: Floting and sinking. 


\section{Appendix}

\section{Survey Questionnaire (Adopted from Yin et al., 2008)}

Dear students

The information gathered through this questionnaire will be used as a part of my study. The responses you provide are completely confidential and anonymous. The research outcome and report will not include reference to any individual.

\section{Section A: Demographic Profile}

1. Gender

$$
\text { a. Male }
$$

2. What is your age group?

3. Class
a. $10-12$
$16-18$

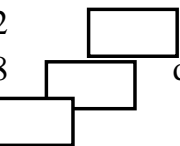

b. $13-15$

d. $18 \&$ above

b. Female

Section B: Please read the questions very carefully and fill in the blanks.

1. Block A and Block B both float in water. Suppose that we glue them firmly together and place them in water; together they will (see the picture below).

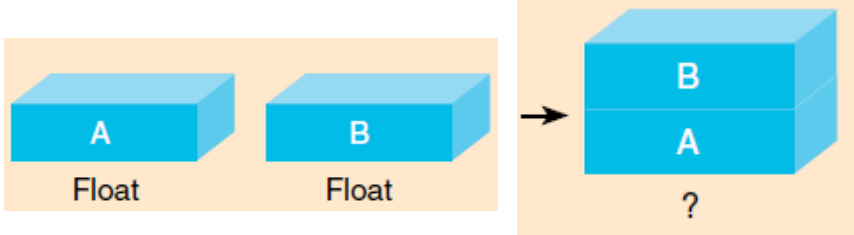

2. Ball A and Ball B are made of different materials, but they have the SAME mass and the SAME volume. Ball A is solid; Ball B is hollow in the center (see the pictures below). Ball A sinks in water. When placed in water, Ball $B$ will

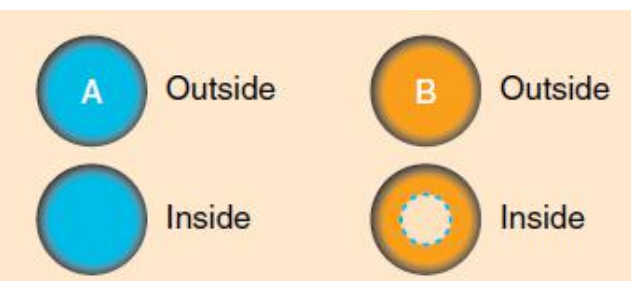

3. Block C floats on water. Suppose we make a hole in it. When placed in water, Block $\mathrm{C}$ will now . (see the pictures below).
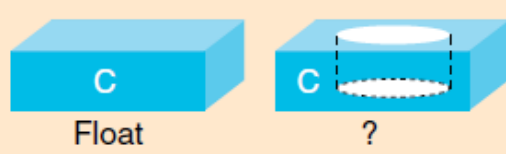

4. Blocks A and B are made of the SAME material. Block B is flatter than Block A. Block A sinks in water. When placed in water, Block B will . (see the pictures below)
B

5. When Block $\mathrm{A}$ is placed in water in the way on the left, it floats in water. Suppose that we flip it upside down and place it in water as shown on the right (see picture below). It will

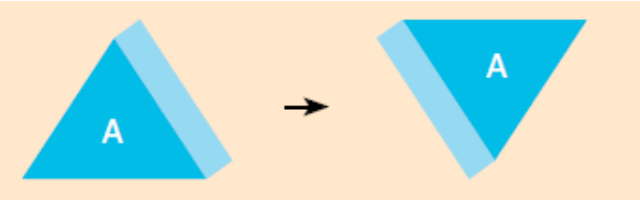

6. Block A sinks in water if we place it in water in the way on the left. If we place it in water in the way on the right, Block A will . (see the picture below)

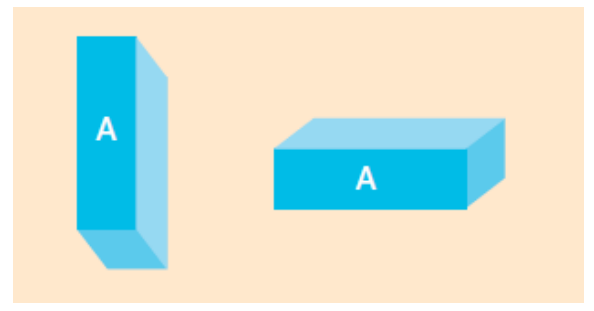

7. Ball $A$ and Ball $B$ have the SAME mass and the SAME volume. Ball A is made of something soft. Ball B is made of something hard. Ball A floats in water. When placed in water, Ball B will . (see the picture below).

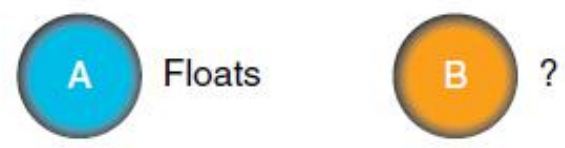

8. Block D sinks in the water in Container 1. When Block D is put in a big container with more water (Container2), Block D will . (see the picture below).

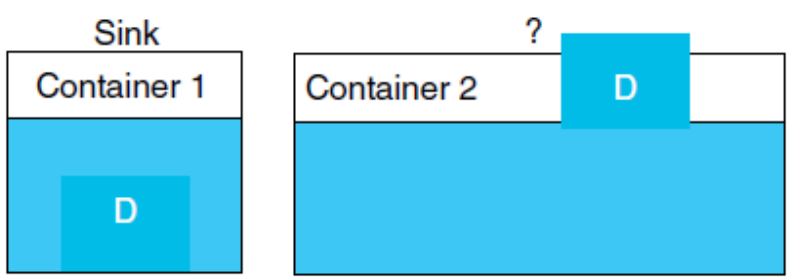

